\title{
Bibliometric Analysis Of Patent Literature Based On Nano-technology Classifications
}

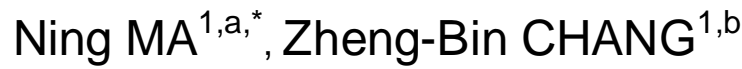 \\ Shanghai Second Polytechnic University, China \\ asummerclause@163.com, bbchang@sspu.edu.cn \\ ${ }^{*}$ Corresponding author
}

Keywords: nano, technical indicators, statistical analysis, bibliometric.

\begin{abstract}
Using bibliometric method, from the nano patent application distributions, legal status, patent types, technology field distributions, inter-division conditions, etc., this paper does quantitative analysis on the nano patents applied in China in order to have an overview of the nano-technology development from a level.
\end{abstract}

\section{Data and methods}

Nano research involves microelectronics, optoelectronics, ceramics, bio-engineering, medical, chemical, computer, aerospace, environment, energy and other fields. In this paper, the authors use Wanfang Patent Database for statistical sources, the retrieval strategy is: in earlier versions, selecting Advanced Search, choosing Patent Name = 'nano' and application Date: 2003-2013, then we get a total of 34,678 patents. After cleaning these data, 34,426 patent data remain. Considering the time lag of 18 months from the application to granting, data of 2012 and 2013 may be incomplete, only for reference. We use bibliometric and patent analytical methods, with the help of Excel and other software tools for data processing and analysis.

\section{Analyses of patent technology indicators}

\section{Nano patent application in domestic}

Since April 1, 1985, China has begun to implement the patent system formally [1]. Up to the statistics date, the application of patents and granting distribution trends are shown in Figure 1. From the growth trend, nano patent applications experienced rapid growth between 2003 and 2011(data of 2012 and 2013 are only for reference because of 18-months' time lag). We can see from the figure 1, the amount of granting patents in this field also had some growth, but the growth rate was lower than the application amount, which might be related to the national policy. The regulations of China's patent law are as follows. Invention patents and utility model patents are first applied and then go to the procedure of censorship, during which there will be a period of 18-month between the filing date and granting [2]. Because patent examiners and ease of patent technologies vary, the time between the date of application and granting differ from each other. To some extent, the amount of granting patents over the years reflects the changing trends of a field in terms of technology better. 


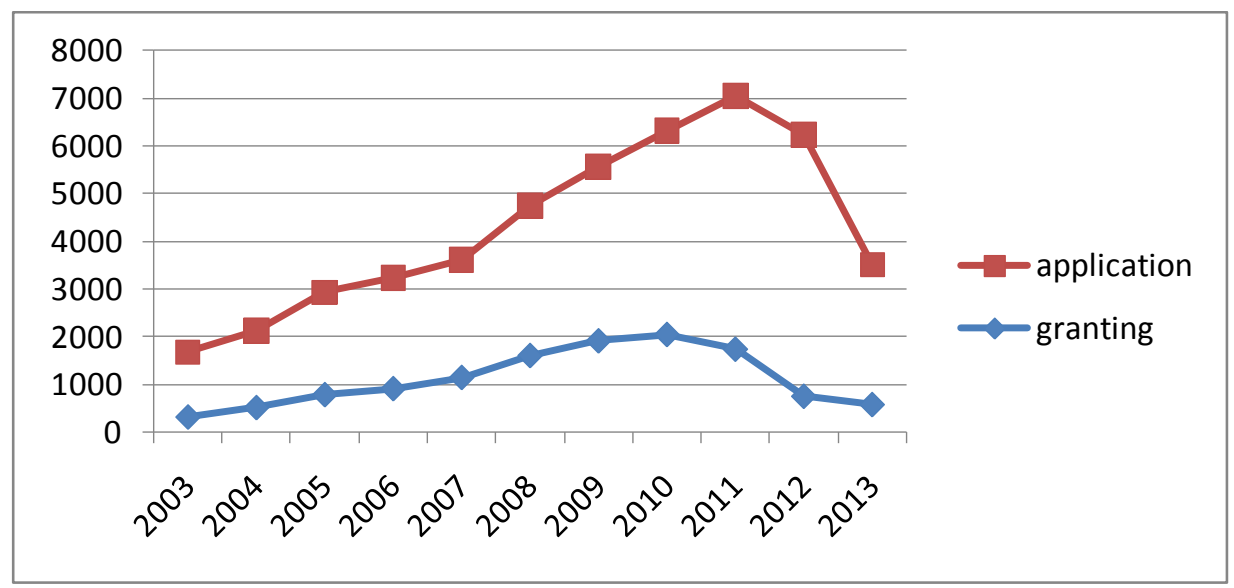

Fig. 1 the amount of nano patent application and granting in domestic

\section{Legal status analysis of nano patents}

Given it is not easy to get the legal status of patent information, many research have not yet paid attention to the legal status of the patent analysis and use. Patent legal status plays a key role not only in the introduction of patents, transferring and the formation of patent allays but also understanding the relevant regions, technology state of enterprise, competitiveness, the average patent quality, awareness of patent protection, $R \& D$ status in specific technology areas[3].

This article divides the legal status of nano patents into three categories 'granting' 'invalidation', 'examination'. According to the Patent law of People's Republic of China enacting on August 25, 2000, 'Granting' refers to the patents granted by the State Intellectual Property Office; 'invalidation' means that patentee has no control of the patents which belongs to world because of failing to pay patent fees, abandonment of a patent, etc.; 'examination' means patents still in the application process. From the data show in Fig 2, 35.67\% of patents were in the state of 'granting', 37.19\% of patents were in the state of "examination", and the ratio of 'invalidation' patents reached at $27.15 \%$ (Fig. 2). According to implementing Rules of the patent law of People's Republic of China enacting on June 15, 2001, patents in the state of 'invalidation', several factors contribute to this. Patent applications are rejected, and patents are unnaturally terminated (unpaid annual fee), withdrawal, lapsed (expiry), in low technical levels, in protection awareness, etc. The government should increase patent $\mathrm{R} \& \mathrm{D}$ investment, continue to strengthen science and technology legislation, improve the efficiency of patent research and development [4].

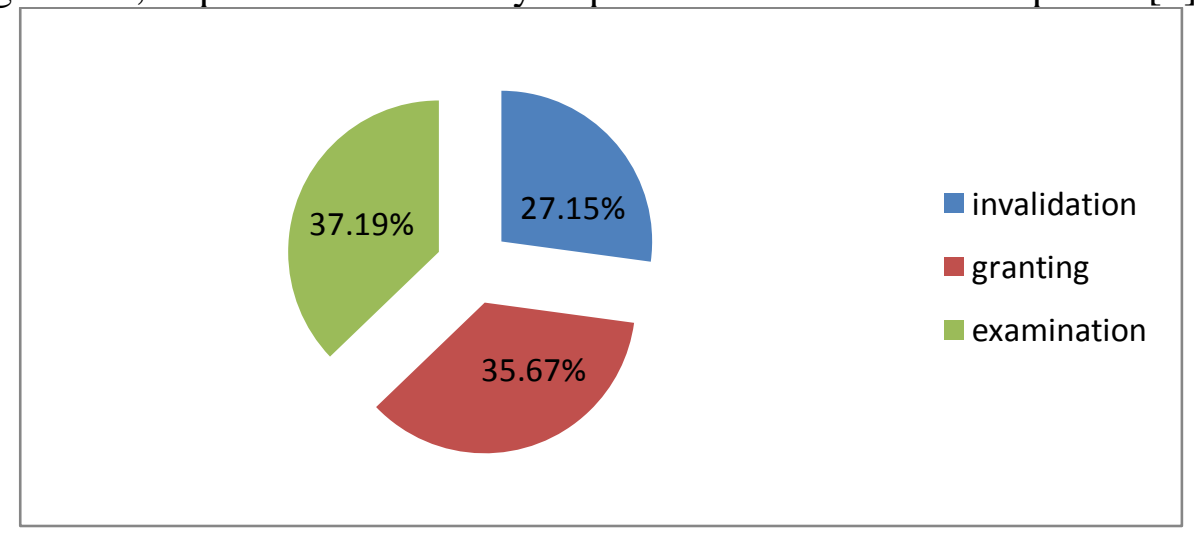

Fig. 2 the legal status distribution of nano patents

Fig. 2 shows that the state of granting, invalidation and examination had a portion of about 1/3 respectively from 2003. As we can be seen from Figure 3, from 2003 to 2008, the amount of granting and examination patents practically equaled with each. After 2008, compared with the 
number of examination patents continuing to increase, the number of granting and invalidation patents continued to decline. This was related to the growth of patentee's patent legal awareness, which made more and more examination patents to grant. Of course, this was also related to annual increase of patent applications. During recent years, in order to enhance the control of the economic value and the strategic value of the nano industry, the state has introduced a number of policies, which may cause the relevant enterprises and research institutions to further develop nano technology to achieve success in the global competition and to get huge economic benefits.

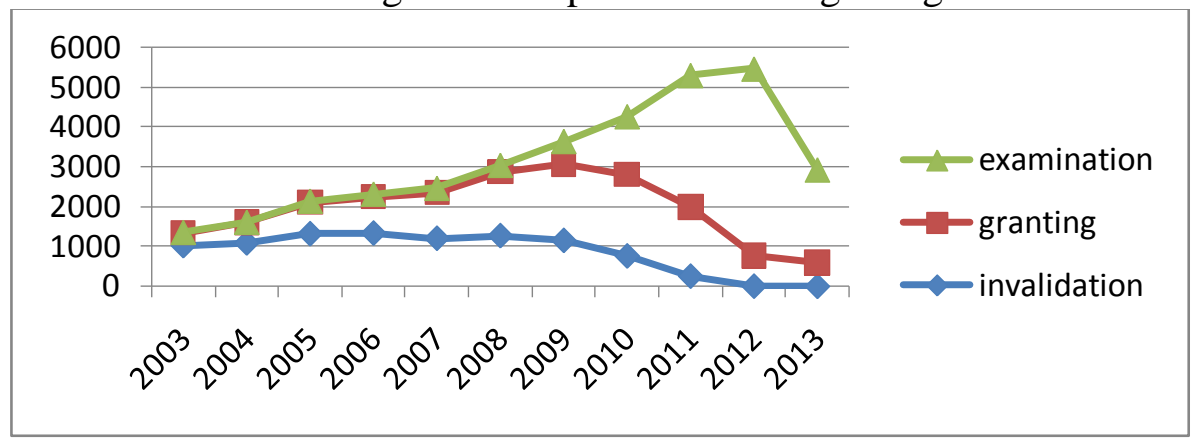

Fig. 3 the annual legal status distribution of nano patents

\section{Nano patent type distributions}

According to the technology difficulties and elements, patents generally include three types, invention patents, utility model patents and design patents respectively. Of all nano patents, the number of invention patents was 31,779 , accounting for $92.31 \%$ of all patents, which portion was much higher than that of utility model patents and design patents. Data also show that in the domestic market, even though nano technology had developed for many years, this industry was still in the stage of repaid development, belonging to a sunrise industry.

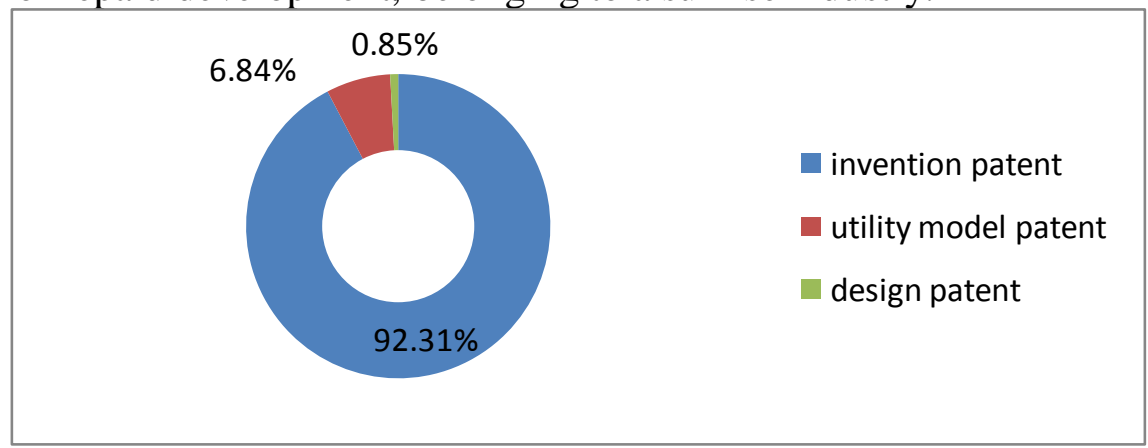

Fig. 4 the distribution of three types of nano patents

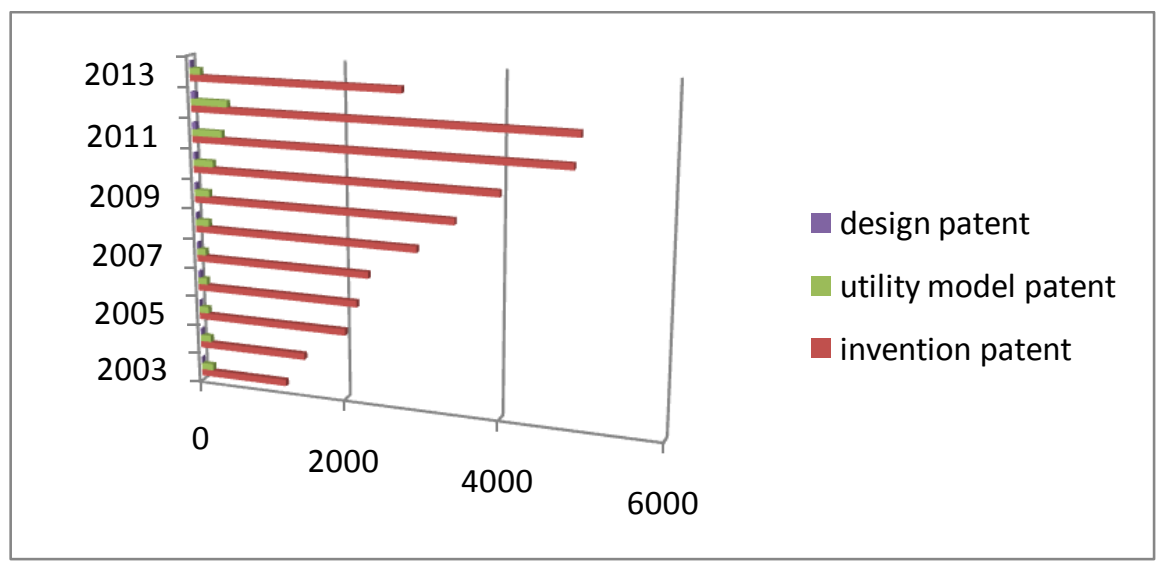

Fig. 5 the annual number of three types of nano patents from 2003 to 2013 


\section{Analyses of technology field distributions}

According to International Patent Classification, the classified objects mainly include invention patents and utility model patents[5].Fig. 6 shows that nano patent applications focused on $\mathrm{C}$ (Chemistry; Metallurgy), accounting for $46.72 \%$, B (operating transport) $17.67 \%$, A (human life must) $11.69 \%$, and nano patents in $\mathrm{C}$ (Chemistry; Metallurgy ) division were most widely used.

There were 112 categories and 386 subcategories in total. Fig. 7 and Fig. 8 show top 20 categories and subcategories respectively. Patents mainly concentrated on $\mathrm{C} 01$ and below that, were C01B. To some extent, these concentration fields of patent applications reflect the main directions of development of nano patents.

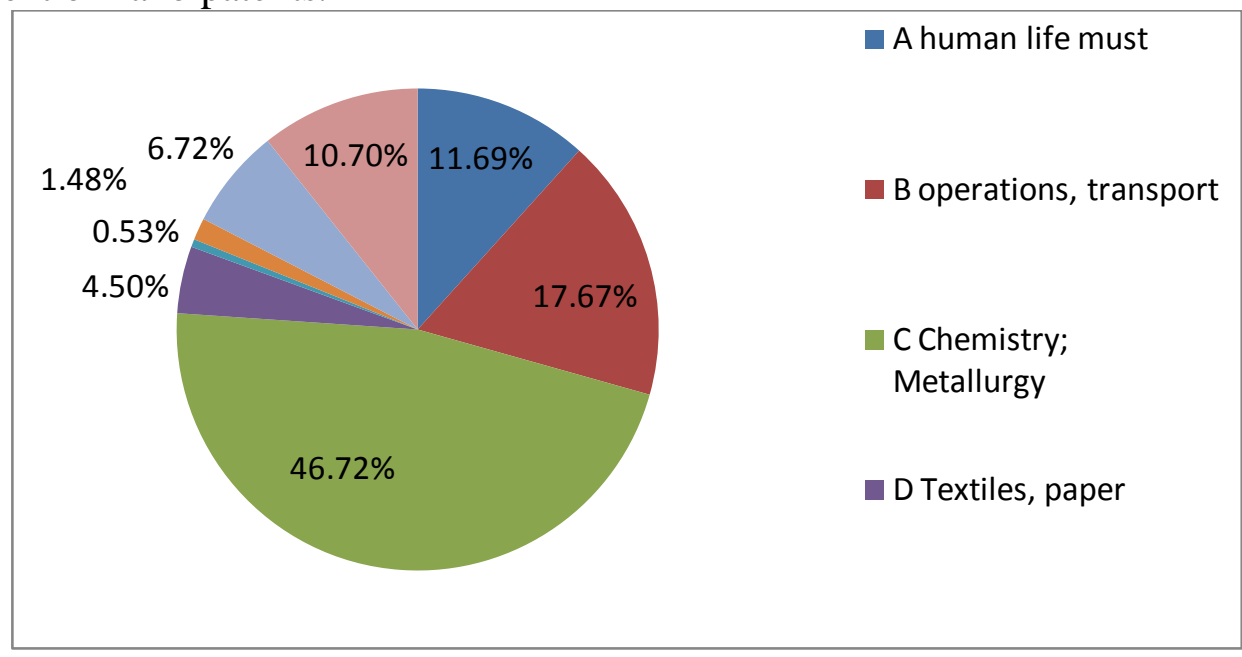

Fig. 6 the constitute of applied nano patents by each division

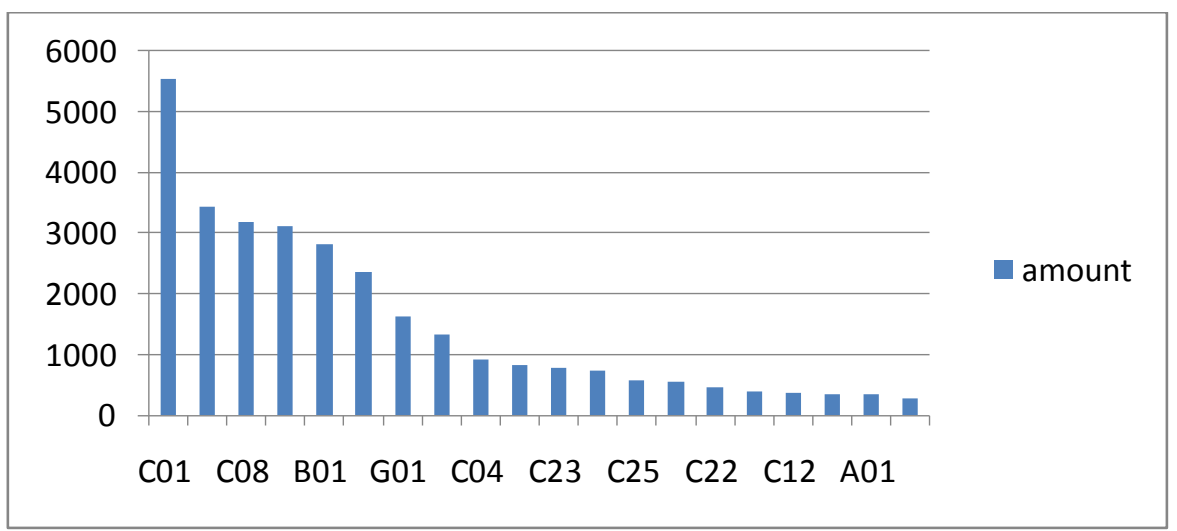

Fig. 7 top 20 of noon patents based on IPC categories

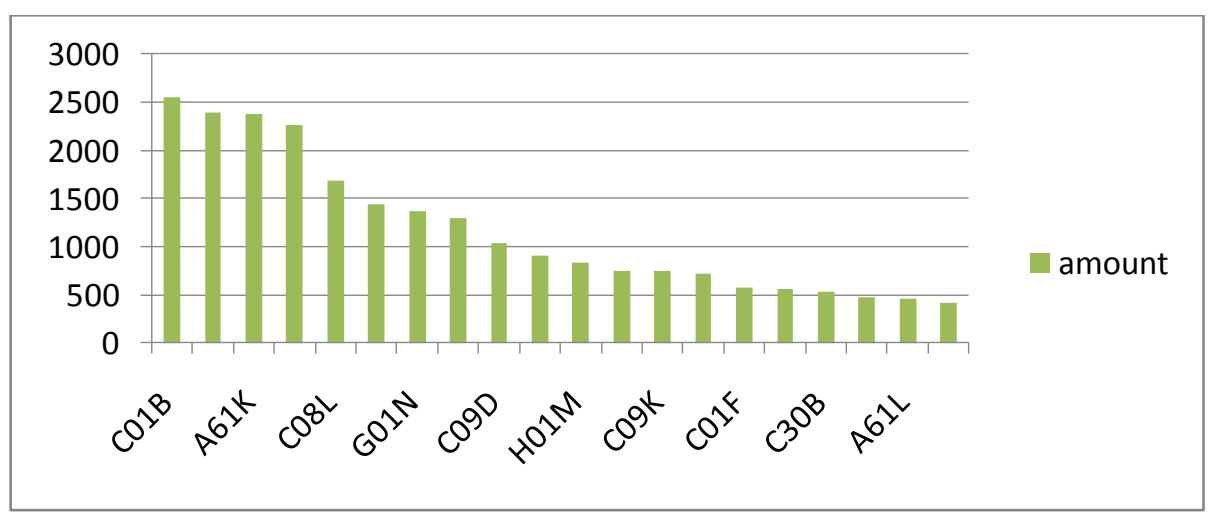

Fig. 8 top 20 of nano patents based on IPC subcategories 
The above analysis was based on patent information such as application date, IPC code to reflect the nano patents status, which was consistent with the current analysis and research of nano patents.

\section{Analysis of inter-division status of nano patents}

It is essential to analyze patent classifications in a certain field. Each classification code represents a technical branch, on behalf of the source of the technology or the future development, and researchers can judge the technical extension and potential development direction in the future. Undoubtedly, nano patents have such attributes. By analyzing the distribution of IPC of nano patents, researchers could discover the depth and breadth of nano technology, which could also provide guidance for the direction of the macro-industry development. Table 1 illustrates that the number of nano patents owning IPC codes varies from 1 to 10, 89.26\% of nano patents had one classification code, $4.05 \%$ of the patents had two codes, involving two technical branches, and $2.65 \%$ of the nano patents had three or more codes, which have a wide technical extension. Meanwhile, according to statistics of inter-division patents, the outcome is shown in Table 2. $95.98 \%$ of nano patents were only in one technical division field, $3.94 \%$ of those involve 2 or 3 divisions. Combining Table 1 with table 2, we found that $89.26 \%$ of nano patents did not have technical extension, $95.98 \%$ of patents' technology only diffused in one division. Data illustrates that nano technology developed relatively narrow and expanded weakly due to its own technology development and social demanding. Combined with the data of patent applications and granting, we could preliminarily judge that China's nano industry was still in a period of rapid development. With the national policy and technology demanding, this industry will accelerate the maturation process in the future.

Table 1 the distribution of IPC of the application of nano patents

\begin{tabular}{|c|c|c|c|c|c|c|c|c|c|c|}
\hline The number of IPC & 1 & 2 & 3 & 4 & 5 & 6 & 7 & 8 & 9 & $>=10$ \\
\hline Application number percentage $89.26 \%$ & $4.05 \%$ & $2.65 \%$ & $1.63 \%$ & $0.94 \%$ & $0.51 \%$ & $0.33 \%$ & $0.21 \%$ & $0.14 \%$ & $0.27 \%$ \\
\hline
\end{tabular}

Table 2 the distribution of the inter-division application of nano patents

\begin{tabular}{|c|c|c|c|c|}
\hline Inter-division & 1 & 2 & 3 & $>=4$ \\
\hline Application number Percentage & $95.98 \%$ & $3.54 \%$ & $0.40 \%$ & $0.08 \%$ \\
\hline
\end{tabular}

\section{Conclusions}

This paper quantitatively analyses nano patent applications, legal status and technology distribution, etc. from 2003 to 2013 in China. During that period, nano patent applications showed a clear upward trend, granting patents grew slowly, and examination patents increased every year. Of all the three types, invention parents accounted for $92.31 \%$, while the failure rate was high, at approximately $27.15 \%$. The rate of technology application was highest in Division C (Chemistry; Metallurgy), within that technology branch, mainly concentrating at $\mathrm{C} 01$ and below that, was C01B. $89.26 \%$ of nano patents did not extend. $95.98 \%$ of patents' technology only diffused in one division. Nano technology developed relatively narrow, with the lack of high technology extension.

\section{Acknowledgement}

This research was financially supported by Training Subsidy Scheme for Shanghai Young Teachers in Universities (ZZegd12009) - -'the research on nano-technology based on patent literature', project number: B51YQ12R008. 


\section{References}

[1] Information on http://news.sohu.com/20100401/n271247728.shtml/

[2] Information on http://www.sc.gov.cn/sczb/lmfl/flfg/200903/t20090331_649924.shtml/

[3] Ernst Holder, Patent Portfolios for Strategic R\&D Planning, J. Journal of Engineering and Technology Management. 1998, 15 (4)279-308.

[4] Chauhan Luan, Baozhan Zheng, Study on Quantitative Analysis of Global patent intensity \& protection of IPR, J. Science\&Technology and Economy.2009, 4(2)55-58.

[5] Information on http://baike.so.com/doc/6709216.html/ 